\title{
Status of laws related to physical protection and radiological emergency in the Republic of Korea
}

\author{
Jaedong Koh, ${ }^{*}$ Sangwon Kim and \\ Changbum Kim
}

Korea Institute of Nuclear Safety, Gusung-dong 19,

Yusung-gu, Daejun 305-338, Korea

E-mail: jdkoh@kins.re.kr

E-mail: K346ksw@kins.re.kr

E-mail: K107kcb@kins.re.kr

${ }^{*}$ Corresponding author

\begin{abstract}
Laws related to atomic energy of the Republic of Korea, which were quite simple at the nascent stage, have been diversified in accordance with the expansion of the nuclear industry and growing public needs. As part of the efforts by the government to address public concerns about nuclear safety, the Act for Physical Protection and Radiological Emergency was enacted to enhance the capabilities to prevent and tackle radiological emergencies and establish a firm mechanism for physical protection. The above act stipulates systematic government-wide measures with a view to preventing radiological emergencies that might possibly occur within the framework of the existing disaster control system of the Republic of Korea and coping with any actual disaster. In addition, the act sets forth a wide range of measures aimed at effectively grappling with acts of sabotage and terrorism related to nuclear facilities and nuclear materials, the importance of which is being increasingly recognised. The Republic of Korea will exert maximum efforts to thwart any unexpected disaster, expecting that enforcement of the act will generate its intended effects.
\end{abstract}

Keywords: laws; radiological emergency; physical protection; disaster prevention.

Reference to this paper should be made as follows: Koh, J., Kim, S. and Kim, C. (2006) 'Status of laws related to physical protection and radiological emergency in the Republic of Korea', Int. J. Nuclear Law, Vol. 1, No. 3, pp.207-218.

Biographical notes: Jaedong Koh is a Principal Engineer of the Korea Institute of Nuclear Safety. With undergraduate and graduate studies in Mechanical Engineering and Welding Engineering, he has worked in various areas in nuclear safety regulation organisations since 1970 s, including safety inspection of nuclear facilities, administration and drafting safety standards, support for the drafting of laws relevant to nuclear safety and national nuclear safety policies, etc.

Sangwon Kim is a Senior Lawyer of the Korea Institute of Nuclear Safety. With undergraduate and graduate studies in public law, he previously worked for an airline company and has worked in the field of legal affairs in KINS, since 1970s. In an organisation, he is preparing and writing draft 
nuclear laws and administering their enactment. He also participates in various works relevant to enactment of domestic laws and international conventions in the field of nuclear energy and nuclear civil liability.

Changbum Kim is a Principal Engineer of the Korea Institute of Nuclear Safety. With undergraduate and graduate studies in Nuclear Engineering and Mechanical Engineering, he has worked in various areas in nuclear power utility companies and KINS since 1970s, including safety review and safety inspection of radioactive materials, administration and drafting safety standards, support for the drafting of laws relevant to radiation safety and national nuclear safety policies, etc.

\section{Introduction}

For the last several decades, competitive and brisk use of atomic energy has played a pivotal role in promoting the economic development of the Republic of Korea. Since the Korean War came to a cease-fire in 1953, tension between the two Koreas has persisted on the peninsula. To brace for potential attacks from the outside, major public and industrial facilities have put in place defence systems in alignment with the military and police. However, past defence systems were aimed at preserving the economic value of nuclear facilities including nuclear power plants. Now, there has arisen another challenge: thwarting any attempt to destroy such facilities or kill and injure ordinary people by using nuclear materials as the so-called dirty bomb. In 2003 and 2004, the Republic of Korea enacted and enforced the Act for Physical Protection and Radiological Emergency and related laws in an effort to beef up the physical protection and radiological emergency measures for major nuclear facilities. This study details the background of the enactment of such laws as well as their significance and major details.

\section{Atomic energy-related laws of the Republic of Korea}

The legal system pertaining to nuclear power in the Republic of Korea has its source in the Atomic Energy Act enacted in 1958. At that time, the nation had no nuclear reactor of any type including research or nuclear power reactor. At the same time, radiation was being utilised in an extremely limited manner. Under the circumstances, the act was enacted due to a special interest in the potential of nuclear power by Lee Seung-man, the first president of the Republic of Korea as well as the general public, the expectations that nuclear power is able to greatly contribute to the development of the nation. The act primarily set forth the establishment of a government agency supervising the use of atomic energy and a research institute to study the peaceful use of atomic energy.

In accordance with the act, the government sets up the Office of Atomic Energy, a central administrative agency headed by a minister-level official and established, under the control of the Office, the Atomic Energy Research Institute, the nation's first national research institute in 1959. In 1962, the Republic of Korea introduced and built the 250W-grade TRIGA Mark-II and 2MW-grade TRIGA Mark-III that were used research 
purpose reactors. The government performed basic scientific research and studies regarding nuclear power by building research reactors and sought to dramatically expand electric power sources to facilitate the economic development of the nation and enhance public living standards, while forcing for the construction of a nuclear power plant, which was deemed as an adventurous attempt at the time. In the early 1970s, the government commenced construction of the country's first nuclear power reactor in the vicinity of a fishing village of the East Sea about 30 miles away from the city with the country's second largest population.

The Atomic Energy Act, which comprised relatively simple provisions, required many modifications in line with construction of the nuclear power plant. In particular, there arose significant changes in radiological protection and safety control requirements concerning construction and operation of a power plant. However, laws to brace for radiological emergencies and promote physical protection were inadequate. Realistically, guarding the security of a nuclear plant was under strict control. Since 1982, massive revisions and complementations of atomic energy laws have been enacted. Until that time, the system of atomic energy laws comprised the Atomic Energy Act as well as multiple presidential decrees and respective corresponding enforcement regulations. With drastic amendments and complementations of the Atomic Energy Act, multiple presidential decrees were consolidated into a single enforcement decree. At the same time, a substantial number of provisions in such decree were modified and added in accordance with the amendments of the Atomic Energy Act. However, there arose a little difference in physical protection and radiological emergency measures in relevant laws.

Other major laws of the Republic of Korea pertaining to the use and development of atomic energy include the Nuclear Damage Compensation Act enacted in 1969, Act on Assistance to Electric Power Plants-Neighboring Areas enacted in 1989 to support the smooth construction of radioactive waste disposal plants and nuclear power plants, Act on Promotion of the Use of Radiation and Radioisotopes enacted in 2002 and the Act for Physical Protection and Radiological Emergency to be detailed in this study.

\section{Enactment of the Act for Physical Protection and Radiological Emergency}

\subsection{Disaster control system and related laws in Korea}

In addition to atomic energy-related laws, the Republic of Korea has enacted laws intended to brace for national disasters including radiological emergencies. Among them are the Framework Act on Civil Defense enacted in 1975, the Disaster Control Act enacted in 1995 as a result of large-scale tragic accidents, which occurred around the nation in the early and mid-1990s, the Framework Act on Disaster and Safety Control enacted in 2004 as a new comprehensive law for the handling of national disasters to replace the Disaster Control Act, comprehensively define national disasters, systemise the mechanism to prepare for and cope with such disasters, and clarify the functions of related government organisations and apparatus, the Countermeasures Against Natural Disasters Act, which sets forth national measures against natural disasters in particular and the Fire Services Act. 
The Framework Act on Disaster and Safety Control stipulates matters necessary to establish the central and local governments' disaster and safety control mechanism for the purpose of preserving the land from various disasters encompassing man-made and natural disasters and protecting people's lives, health and property and to prevent, brace for, respond to and recover from disasters. Figure 1 summarises the major disaster control system under such an act.

Figure 1 National disaster management system of the Republic of Korea

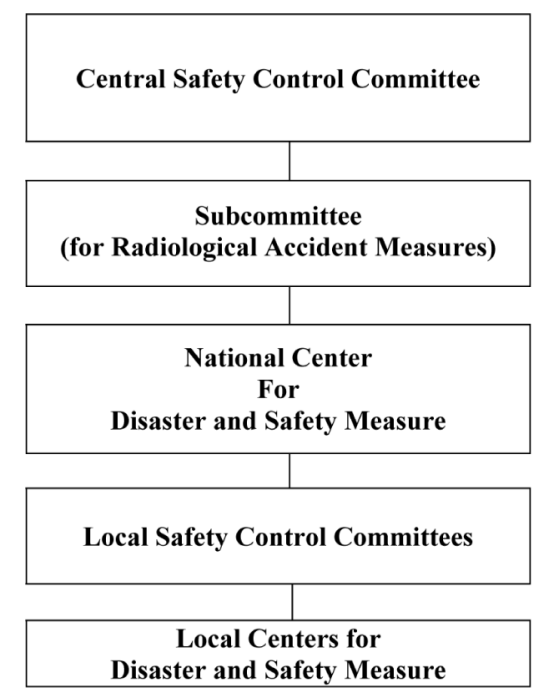

Chairman: the Prime Minister
Members: 25 persons including relevant ministers
Duties: Deliberate major disaster control policies and

formulate basic plans on national safety control

Chairman: Minister of Science and Technology

Duties: Execute matters related to radiological measures

among the duties of the Central Committee

Chief: Minister of Government Administration and Home

Affairs

Duties: Respond to and facilitate recovery from large-scale

disasters

Chairman: Heads of local governments

Duties: Handling the local affairs of the Central Safety Control Committee

Chief: Heads of a local governments

Duties: Respond to and facilitate recovery from local disasters

The Act on Countermeasures Against Natural Disasters stipulates necessary matters related to the prevention of and recovery from natural disasters and other relevant countermeasures to preserve the land and protect people's lives, health and property as well as major infrastructure facilities from a part of disasters defined in the Framework Act on Disaster and Safety Control (disasters triggered by natural causes).

The Framework Act on Civil Defense stipulates self-defensive activities, which must be performed by the populace under governmental guidance including air defence, emergency measures, rescue, restoration, and support for necessary efforts under military operations to protect people's lives and property from invasion by an external enemy or prevent a disaster, which might jeopardise the safety and order of the entire nation or some parts of it (an event requiring civil defence). It also contains various provisions that can be applied in coping with various disasters and implementing posterior actions. The Framework Act on Disaster and Safety Control is a basic and comprehensive law pertaining to disasters devised to tackle all kinds of disasters including natural disasters such as a typhoon, flood and earthquake, and man-made disasters arising from accidents (including radiological emergencies). For instance, Article 8(1) of the act requires that all other disaster-related laws in the Republic of Korea should be enacted or amended in accordance with the act. Therefore, it is deemed that the Act for Physical Protection and Radiological Emergency or the Countermeasures Against Natural Disasters Act constitutes detailed and specific laws under the control of said act. A comparison between these laws and the Act for Physical Protection and Radiological Emergency is presented in Table 1. 
Table 1 Comparison of major details of laws related to disaster prevention

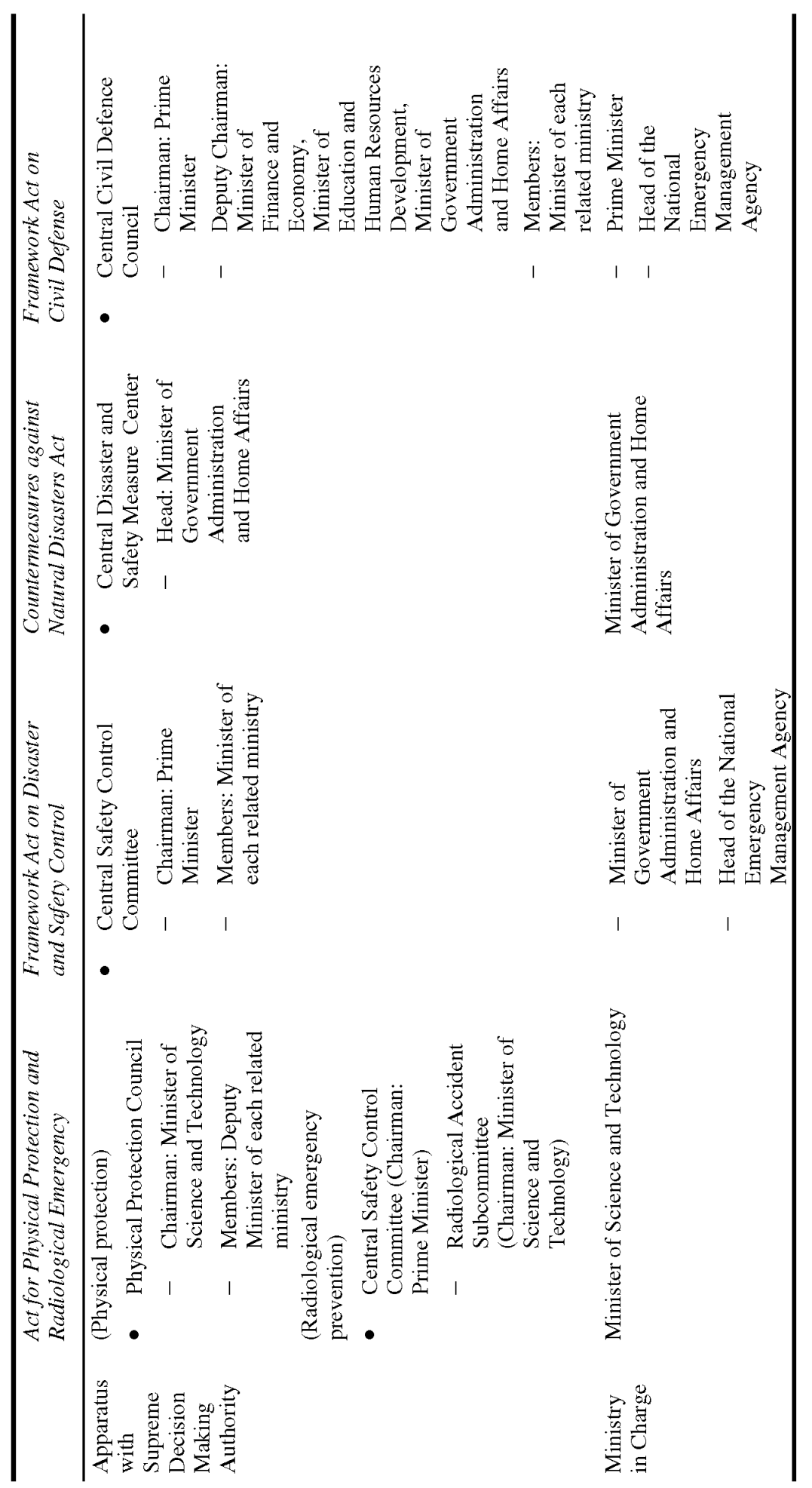


Table 1 Comparison of major details of laws related to disaster prevention (continued)

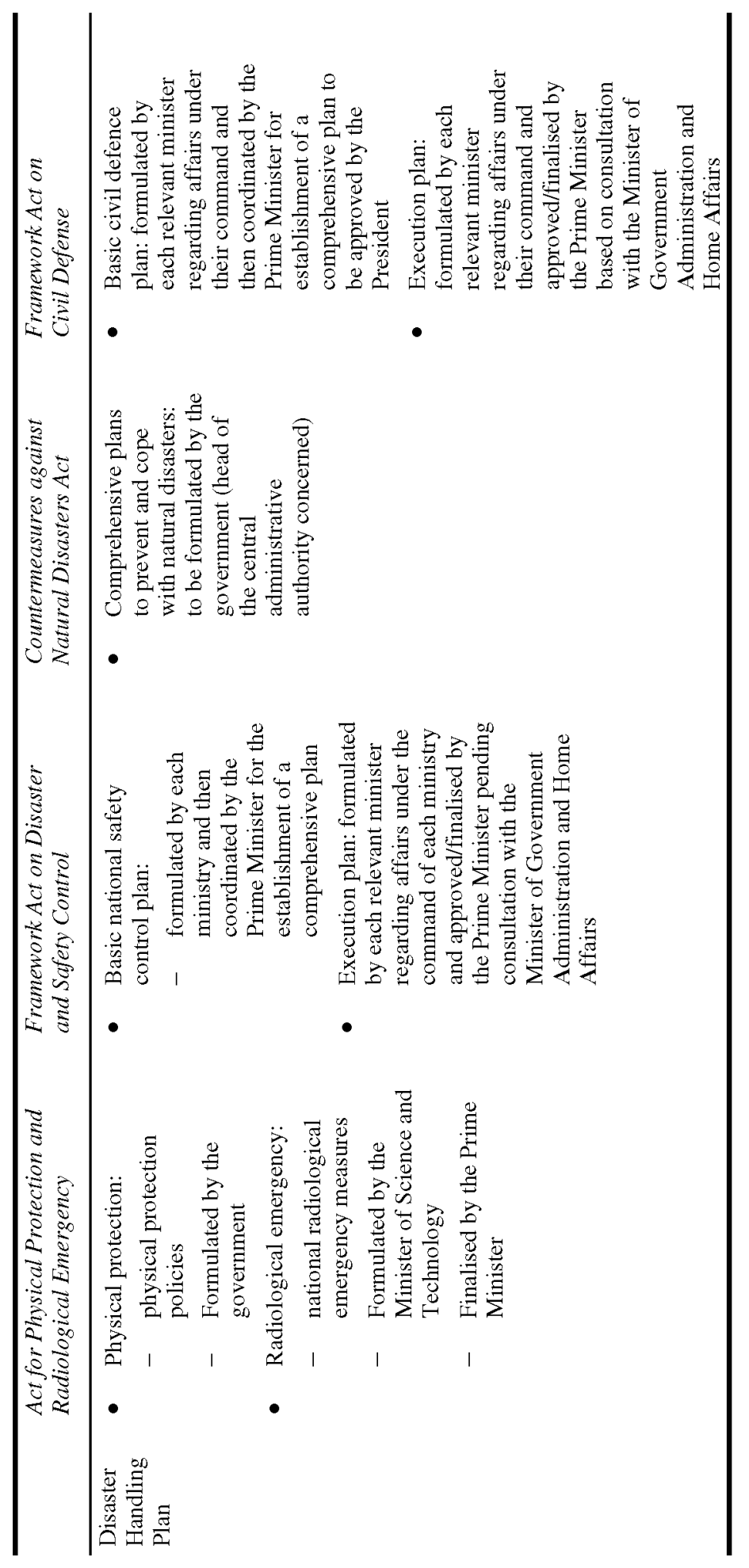


Table 1 Comparison of major details of laws related to disaster prevention (continued)

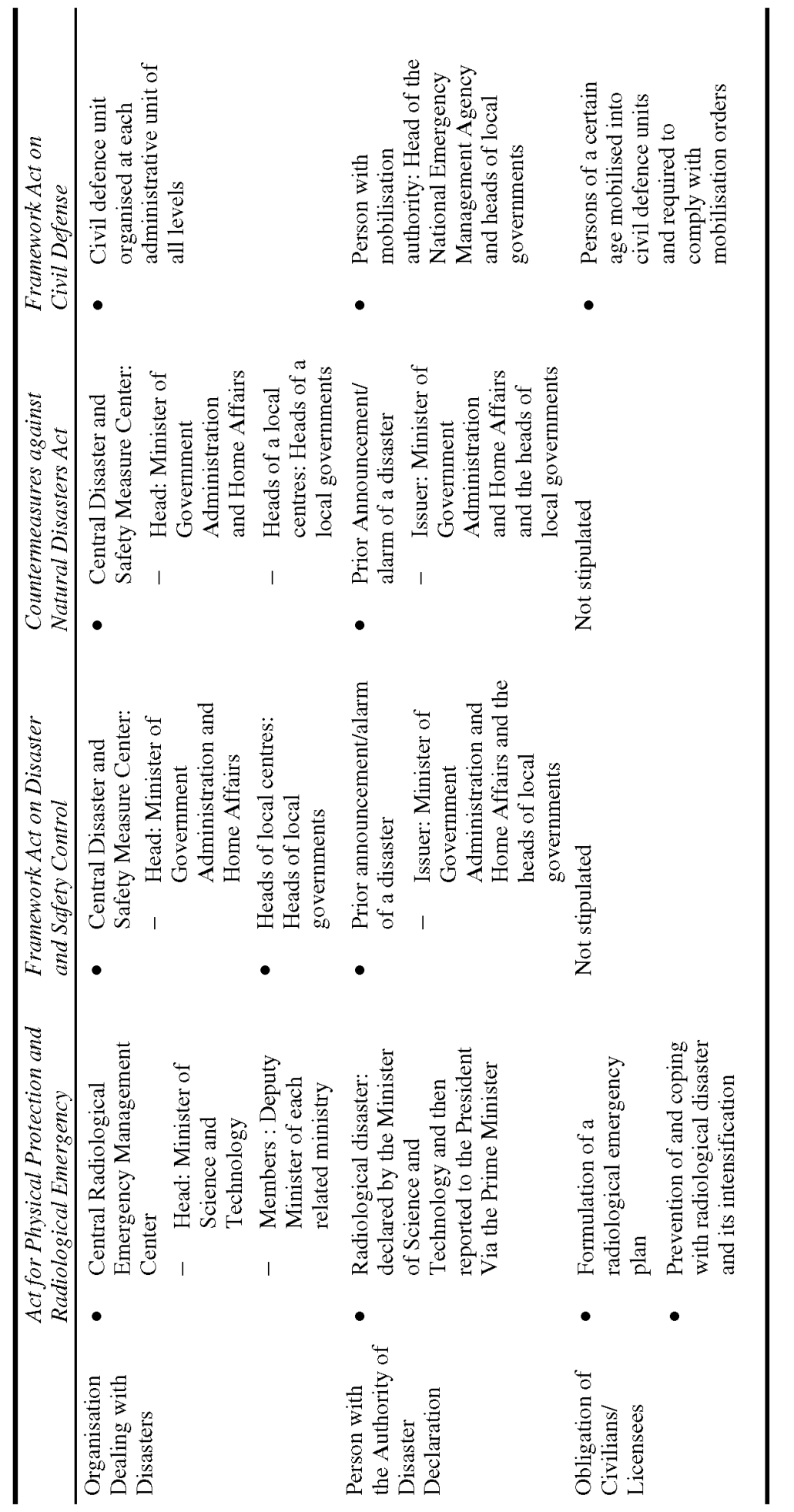




\subsection{Background of enactment of the Act for Physical Protection and Radiological Emergency}

In pushing for the construction and operation of the Gori Nuclear Power Plant I, the first nuclear power plant in the nation, major matters were stipulated in the Atomic Energy Act with reference to nuclear energy safety-related laws of countries such as the USA and Japan as regards nuclear plant design, construction and operation to ensure the safety of the nuclear plant. At that time, there was little awareness in the Republic of Korea for the possibility of a massive radiation leakage at commercial nuclear power generation facilities. The 1974 WASP 1400 report prepared by the USA noted the possibility of a large-scale core meltdown accident. However, the Republic of Korea judged that a radiation leakage accident was unlikely to the extent that rigorous design standards (e.g. general design standards of the USA, etc.) were met and the conditions for safe reactor operation were complied with to prevent such an accident.

However, the TMI accident showed that a massive radiation leakage at a nuclear power plant, which scientists and engineers had played down as a mere possibility, might actually occur, contrary to existing expectations. The government of the Republic of Korea became more aware of the importance of the safety of nuclear power generation, which was in its embryonic stage as well as radiological emergency measures. In addition, the government exerted an effort to enable its population to have a sense of security. At that incident, the Republic of Korea was building its second and third nuclear plants, operating its first nuclear plant, which was put into operation in 1978. The TMI incident made evident the need to expand the scope of countermeasures against radiological disasters. Thus, the Republic of Korea came to press ahead with the enforcement and execution of measures against radiological disasters covering not only employees of nuclear plants, but also people living near nuclear plants and the surrounding environment. Attainment of such goals required active participation and support by the central administrative agencies with the authority of permitting construction of nuclear power plants as well as local administrative bodies and governments, which had nuclear facilities in areas under their control.

However, the government of the Republic of Korea sought to operate radiological emergency measures within the legal framework of the then existing disaster-related measures and civil defence-related laws formulated to brace for national disasters or cope with emergencies, while taking substantive actions to expedite radiological emergency measures. Thus, it did not take into account possible enactment of separate laws in connection with radiological emergency measures. It merely took such minimal actions as prescribing the submission of a radiological emergency plan by a nuclear licensee, as a document to apply for a permit to operate nuclear plant facilities, under the relevant provisions of the Atomic Energy Act.

Concerning physical protection, a state intelligence agency and the Ministry of National Defense were involved in safeguarding the security of nuclear plant facilities, as they were classified as major national industrial facilities. In addition, KEPCO, which was the licensee of nuclear power plant at the time, was subject to security measures by the government as it was under the supervision of the energy-related central government authorities. In the mid- and late-1990s, however, the government of the Republic of Korea started to devise stronger measures to prevent radiological emergencies and protect nuclear facilities from and against threats of nuclear material thefts by acts of terrorism in the face of radiation leakages at home and abroad and the 11 September 
terrorist attacks. As part of such efforts, the country formulated a law that sets forth national radiological emergency/physical protection measures in a specialised manner. The law contained provisions on physical protection measures aimed at protecting the safety of nuclear facilities from terrorism and sabotage from the perspective of reinforcing and further detailing the provisions of the existing Atomic Energy Act as regards radiological emergency measures and meeting the demand for stronger protection of nuclear facilities by parties to the international non-proliferation regime.

The Act was promulgated by Act No. 6873 on 15 May 2003. Its Enforcement Decree and Enforcement Ordinance were respectively promulgated and enforced by Presidential Decree No. 18341 as of 29 March 2004 and by Ordinance of the Ministry of Science and Technology No. 55 as of 20 May 2004.

\section{Major details of the Act for Physical Protection and Radiological Emergency}

\subsection{Major duties of the central/local governments and nuclear licensees}

The state shall set physical protection objectives as regards preventing illicit trafficking of nuclear materials and sabotage of nuclear facilities and nuclear material as well as establishing a mechanism of physical protection. The Physical Protection Council shall be set up and operated under the Minister of Science and Technology for the deliberation, supervision and coordination of major policies regarding the physical protection. The Minister of Science and Technology shall assess threats to nuclear facilities, etc. and formulate response standards by threat every three years for the implementation of physical protection policies. In addition, the central and local governments shall formulate radiological emergency plans. To effectively respond to radiological disasters, central and local agencies in charge must be set up and an organisation to support response to a radiological accident installed at the site of an accident. In addition, the national radiological emergency medical system must be formed, together with the national radiation emergency medical centre. It is also required to assess the mid- to long-term radiological impact of a radiological disaster, formulate/execute damage restoration measures and posterior actions and perform disaster investigations and so forth.

Nuclear licensees shall establish physical protection facilities and their operational systems concerning the relevant nuclear facilities and obtain the approval thereof from the Minister of Science and Technology. Nuclear licensees shall also formulate regulations for physical protection of nuclear facilities and planned measures against illicit trafficking of nuclear materials and threats to nuclear facilities ("protection emergency plans') and obtain the approval thereof from the minister. With respect to radiological emergencies, facilities and equipment necessary to cope with a radiological disaster shall be secured as provided by related laws. In addition, relevant employees shall undergo radiological emergency training and radiological emergency exercises as set forth in related laws. Prior to commencement of the operation of nuclear facilities, a radiological emergency plan must be established and approval thereof from the Minister of Science and Technology be obtained. Nuclear licensees assume the obligations to submit a report in the event of a radiological accident, install related 
safety mechanisms, disclose relevant information, take emergency actions to prevent the spread of a radiological accident and perform other measures deemed necessary to cope with radiological disasters.

\subsection{National radiological emergency prevention measures and mechanism}

\subsubsection{Declaration of radiological disasters}

In the event of a radiological emergency at a nuclear facility, a nuclear licensee must report such event to the Minister of Science and Technology and the head of the related local government. Radiological emergencies are classified into an alert, site area emergency, general emergency and other abnormalities. The Minister of Science and Technology who receives given report must declare a radiological disaster and promptly make a report to the Prime Minister and the President. A radiological disaster is declared only when the radiation exposure quantity or space radiation dose rate exceeds the level provided by related laws (Article 25 of the Enforcement Decree of the Atomic Energy Act) and when the Minister of Science and Technology acknowledges, in his reasonable discretion, that it is necessary to declare a radiological disaster.

\subsubsection{Radiological emergency planning}

The central government, local governments and nuclear licensees, respectively, are required to formulate appropriate radiological emergency plans. They comprise three-staged emergency plans including national radiological emergency plans by the central government, local radiological emergency plans by local governments such as metropolitan city/province and city/county/district and nuclear licensees' radiological emergency plans. In particular, when a nuclear licensee formulates a radiological emergency plan, prior consultation with a local government and local administrative authorities shall be conducted. National radiological emergency plans at the level of the central government comprise radiological disaster-related plans and civil defence plans among the national disaster management plans pursuant to the Framework Act on Disaster and Safety Control and the Framework Act on Civil Defense. The efficacy of such radiological emergency plans shall be reviewed each year for their complementation. The Minister of Science and Technology shall examine such emergency plans and rectify/supplement them when and as necessary.

\subsubsection{Apparatus and mechanism to cope with radiological disasters}

Related laws including the Framework Act on Disaster and Safety Control and the Act for Physical Protection and Radiological Emergency provide for the installation of apparatus and organisations necessary to cope with radiological disasters. According to the Framework Act on Disaster and Safety Control, the central government shall organise the central safety measures committee, which deliberates, supervises and coordinates major governmental and local policies regarding radiological disasters.

The Act for Physical Protection and Radiological Emergency provides for the organisation and operation of the national emergency management committee headed by the Minister of Science and Technology, the local emergency management centre mostly headed by metropolitan city mayors/provincial mayors and the emergency operations centre of the relevant nuclear licensee actually undergoing a radiological emergency, 
as the organ that deliberates, supervises and coordinates major policies regarding radiological emergency measures. The national emergency management committee, which consists of its head, the Minister of Science and Technology and deputy ministers of 11 related ministries, receives reports on and supervises activities by the heads of the on-site emergency management centre, radiological emergency technical advisory centre and radiological emergency medical service centre.

\subsubsection{Implementation of radiological emergency prevention education and exercises}

It is compulsory to conduct radiological emergency training targeting employees of nuclear licensees, radiological emergency staff of local governments in an emergency planning zone, radiological emergency medical staff and so on. In an attempt to brace for potential radiological emergencies, local governments and nuclear licensees in an emergency planning zone must jointly conduct radiological emergency exercises on a regular basis. Every five years, central administrative authorities, relevant local bodies and governments and nuclear licensees are required to participate in a combined exercise. Under the existing laws, the next such combined exercise is slated for 2006.

Various radiological emergency exercises are carried out according to scenarios of radiological emergencies, including responses by the emergency staff, evacuation (dispersion) of the population, containment of fire, medical rescue activities, as well as checking of radiation inside and outside a power plant. These exercises are aimed at checking the overall capabilities to respond to a radiological emergency, minimise damage to the populace and environment and protect the residents, in addition to strengthening the cooperative system among the organisations related with radiological emergencies. Radiological emergency exercises include independent exercises implemented by Korea Hydro and Nuclear Power (a nuclear licensee) and comprehensive exercises conducted by central and local governments in conjunction with relevant institutions.

\section{Conclusion}

All nuclear projects underway in the Republic of Korea have been implemented within the framework of peaceful use as accepted by the international community. However, the threats of terrorism and sabotage against nuclear facilities can never be underestimated, given the complexities of current international politics. In addition, the complicated nature of elements and systems pertaining to the operation of nuclear facilities makes it impossible to eliminate the possibility of radiation leakage from nuclear facilities completely and permanently. Despite this situation, it is of the paramount importance to constantly make efforts towards minimising such possibility and to strive for the prevention of a radiological disaster and minimisation of its consequences in the densely populated Republic of Korea. In particular, the fate of the domestic nuclear industry may be determined according to such endeavours towards ensuring safety. With the enforcement of laws related with nuclear facilities protection and radiological emergency measures, relevant actions and measures necessary in these areas now possess the requisite legal rationale. This will further enhance the Korean people's trust in the safety of nuclear facilities. 


\section{Bibliography}

Act for Physical Protection and Radiological Emergency of the Republic of Korea, 2004.

Lim, Y.K. (2004) 'A study on execution program of training for emergency response plan against radiological disasters', Korea Academy of Nuclear Safety.

Park, W.J. (2004) 'A study on establishment of comprehensive response plan for radiological emergency', MOST. 